\title{
TO BE OR NOT TO BE GREEN? THE CHALLENGE OF URBAN SUSTAINABLE DEVELOPMENT IN THE POST-SOCIALIST CITY. CASE STUDY: CENTRAL AND EASTERN EUROPE
}

\author{
PhD Student Alexandra SANDU ${ }^{1,2}$ \\ ${ }^{1}$ University of Lyon, CNRS, University Lumière Lyon 2, EVS, UMR5600, F-69007, France \\ ${ }^{2}$ University Alexandru Ioan Cuza of Iasi, Faculty of Geography and Geology, Department of \\ Geography , Romania
}

\begin{abstract}
The sustainable development is an important issue for our society. Thus, urban green spaces are a key element in order to assure a sustainable urban development. Although, most often they are associated as having only an aesthetic function, the urban green spaces perform important socio-economic and environmental functions. Therefore, ensuring the existence of a great number of green spaces within an urban area is one of the objectives of the new European policies for urban planning, taking into account the sustainable urban development trend promoted by the new European strategies and also the fact that in the last decade we have been confronted to an intensive land artificialization due to the extensive phenomenon of urban sprawl. Thus, the purpose of this research is to analyze the spatial distribution of green urban spaces in the Central and Eastern European post-socialist countries, members of the European Union, as well as the population accessibility to the green urban spaces. The main question of the study is how the EU urban planning policies has influenced the countries from the Central and Eastern Europe in maintaining and developing the urban green spaces. Do they assure an equitable accessibility to the urban green spaces for all the population in their fastest developing cities of their countries - the capitals? Or are there spatial disparities in what concerns their location patterns? Using a quantitative methodology, doubled by the use of GIS tools and statistics, this research aims to question the eventual typologies regarding the spatial distribution of green spaces as well as their quantitative aspects (their number, the area etc.).
\end{abstract}

Keywords: green urban areas, GIS, Central and Eastern Europe, post-socialist city, EU, sustainable development

\section{INTRODUCTION}

In the international context of promoting a sustainable development, the need to adopt national, regional and local policies to favor it, it is undeniable. Urban green areas are without a doubt, a key element in ensuring better living conditions for citizens in major urbanized cities and they play an important role in what concerns the sustainable development of a highly-urbanized city. Not only do they perform aesthetic functions, they also do perform socio-economic, environmental and health functions. According to 
the "Europe 2020" Strategy[7], at least 5\% of the European Regional Development Fund (ERDF) resources allocated to each member state are to be invested in actions that will set the course for a sustainable urban development. Therefore, there is no doubt that they represent a highly important element that assures the sustainability of an urban area, as it represents the reminiscences of nature in an artificialized area. [1] Therefore, preserving the green urban spaces (parks, public gardens etc.), as well as creating space for new ones, if possible, should be one of the main aims of the urban development strategies and policies in the context of the sustainable urban trend promoted by the European Union.

Hence, this paper address the problem of an uneven and uncontrolled urban development in what concerns the green areas in the post-socialist era in the capital cities of the Central and Eastern European countries, members of the European Union. Taking into account that the main focus of the socialist era was the economic progress through a massive industrialization, it comes as no surprise that one particularity of the urban areas from this part of Europe have a high degree of soil artificialization, while the open and green spaces are less present. However, one would think that with the reintegration in the overall European dynamics and trends to promote a sustainable development, these countries would give a bigger importance to maintaining the already existing green urban areas and even creating new ones in order to increase the quality of life for the population in urban areas that become more and more crowded with buildings.

The main objectives of this research question the problem of green urban spaces in terms of potential accessibility, spatial distribution patterns and quantitative aspects. Therefore, the main research questions can be structured as it follows: What are the general spatial patterns in what concerns the localization of green urban areas? Is there a specificity for each country? Or are there any regional particularities, taking into account their shared-history and past?

\section{MATERIALS AND METHODOLOGY}

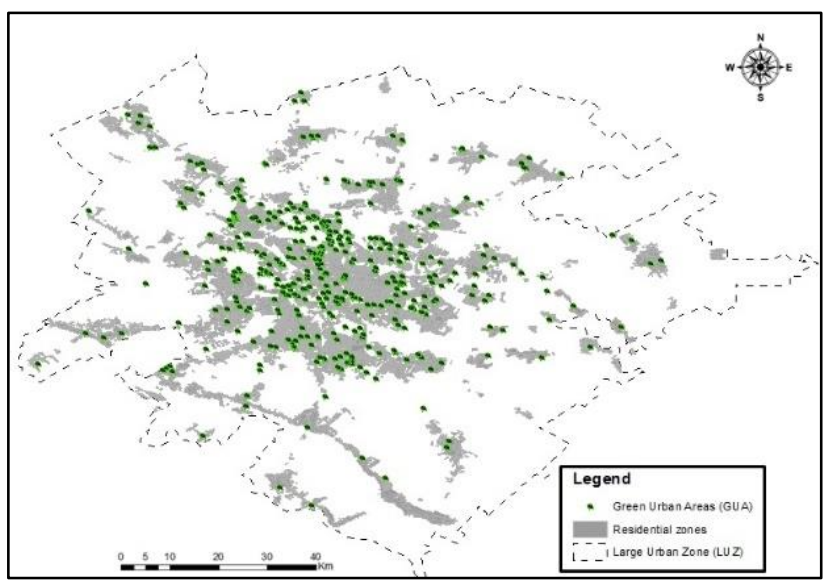

Figure 1 - The 6 classes analyzed (Source : GMES Urban Atlas, EEA)
The GMES Urban Atlas 2006 and 2012 databases[10] developed by the European Environmental Agency (EEA) were used to derive the quantitative specificities of the green urban areas in the capital cities of the countries from Central and Eastern Europe. These databases show a detailed type of land-cover in the 27 countries of the European Union (scale: 1:100.000; MMU: 25 ha) for the urban areas with more than 100 000 inhabitants, as defined by the Urban Audit for the reference year 2006.[9] The land-cover maps for each city are classified into 20 classes depending on the type of land use (e.g. residential, industrial and commercial, green spaces, airport etc.). For this study, it was worked with only 6 classes that grouped the focuses areas of our analysis (see Table 1 and Fig. 1) 
Table 1 - The description of the classes used in the study (Source : GMES Urban Atlas, EEA)

\begin{tabular}{|c|}
\hline 1. RESIDENTIAL CLASS - predominant residential use \\
\hline Continuous Urban Fabric - Sealing degree of soil - above $80 \%$ \\
\hline Discontinuous Dense Urban Fabric - Sealing degree of soil :50\%-80\% \\
\hline Discontinuous Medium Density Urban Fabric - Sealing degree of soil : $30 \%-50 \%$ \\
\hline Discontinuous Low Density Urban Fabric - Sealing degree of soil : $10 \%-30 \%$ \\
\hline Discontinuous Very Low Density Urban Fabric - Sealing degree of soil : $<10 \%$ \\
\hline 2. GREEN URBAN AREAS (GUA) - public green areas (forests are not included ) \\
\hline
\end{tabular}

The methodology of the study consists of a complex of statistics and GIS methods that allowed the quantification of the spatial patterns of green urban areas as well as their quantitative aspects. The network analysis, which represents a common analysis when one wants to assess the accessibility to public facilities such as green spaces $[2,3,5]$ was done with the aid of software ArcGIS 10.3, using the Network Analyst extension tool. Furthermore, the shortest distance path from a residential area to an urban green area, as well as the median and the maximum distance were calculated using the road network derived from Open Street Map[11]. The median distance was preferred, rather than the average distance as it gives a clearer idea regarding the spatial disparities in the distribution of the green areas. Additionally, directional distribution was

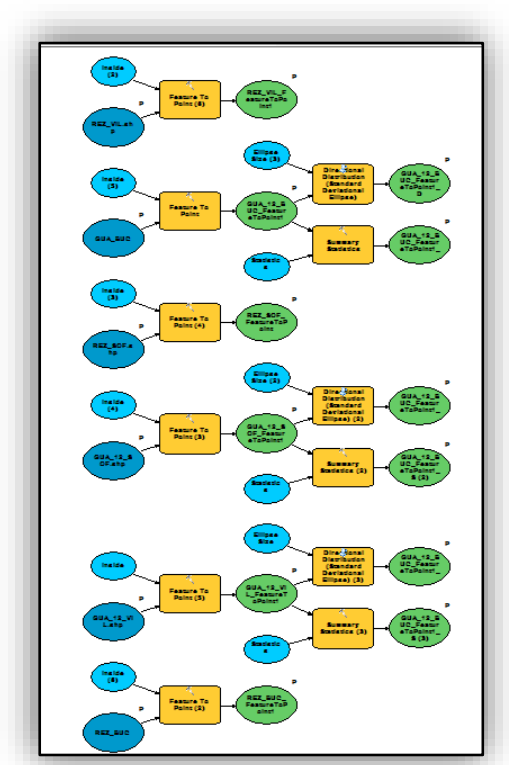

Figure 2 - Workflow in ArcGIS (standard deviational ellipse) calculated to give us even more information about the spatial patterns of green urban areas. (see fig.2). The shortest distance path was obtained using Closest Facility Layer from Network Analyst. Also, the growth rate and green urban area per capita were derived from statistics from the GMES Urban Atlas databases.

\section{RESULTS AND DISCUSSION}

\subsection{Results}

One of the main indicator used by the World Health Organization(WHO) [8] in assessing the quality of life of the population as well as the green space coverage in an urban area is represented by the green area per inhabitant, which according to WHO it should be a minimum of $9 \mathrm{~m}^{2}$. Analyzing the figure 3 , one could observe the great variety of the values obtained for each capital city, the smallest value being that of Bucharest (Romania) which is just below the limit of WHO. Ljubljana, Bratislava, Sofia and Budapest also come around the limit, but still they are above. The biggest values are obtained for Vilnius and Warsaw, while the other 3 studied cities have average values. 


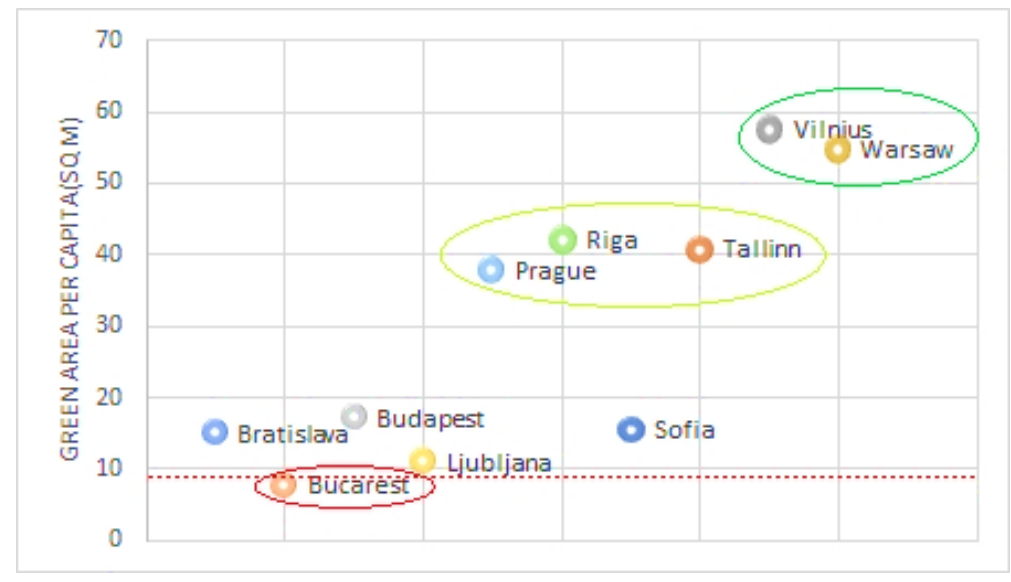

Figure 3 - Green area per inhabitant (m2) (Data source : GMES Urban Atlas)

In what concerns the growth rate of the green urban areas during the 6 years covered by the databases, it should be noted that the biggest value is obtained by Tallinn, followed by Warsaw while Vilnius records a negative rate. No growth is observed for Bratislava and Ljubljana, while Budapest and Riga records also small decreasing rates. Sofia, Prague and Bucharest show a very small growth trend. (see fig.4)

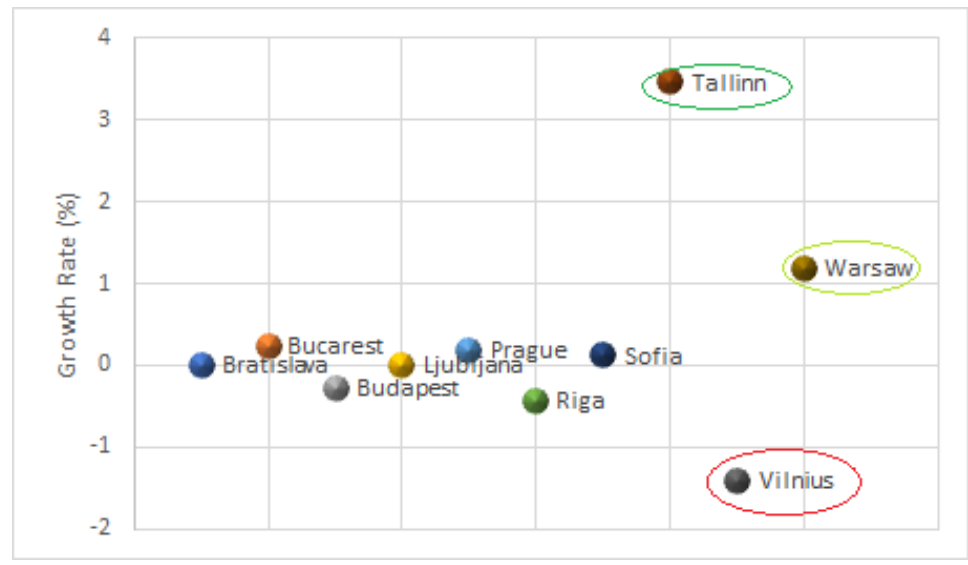

Figure 4 - The growth rate of green urban areas (Data source : GMES Urban Atlas)

Analyzing the maps for each capital city (see fig. 3), one could observe some similarities, but in the same time more differences in what concerns the spatial distribution of green urban areas, as well as the spatial accessibility of population to the green areas. In fact, a common characteristic is the small number of green urban areas that could be found in the outskirts of the capital cities, therefore resulting in overall spatial disparities in what concerns the potential accessibility of the population. (ex. Vilnius, Ljubljana, Prague etc. - see Fig. 5). Also when analyzing the directional distribution of the GUAs in the capital cities, one could observe a variety of trends alternating from $\mathrm{N}$ - E direction (Vilnius) to S-SE one (Bratislava), the most common directional tendency being the E- W (Riga, Tallinn etc.) (see Fig. 5). 


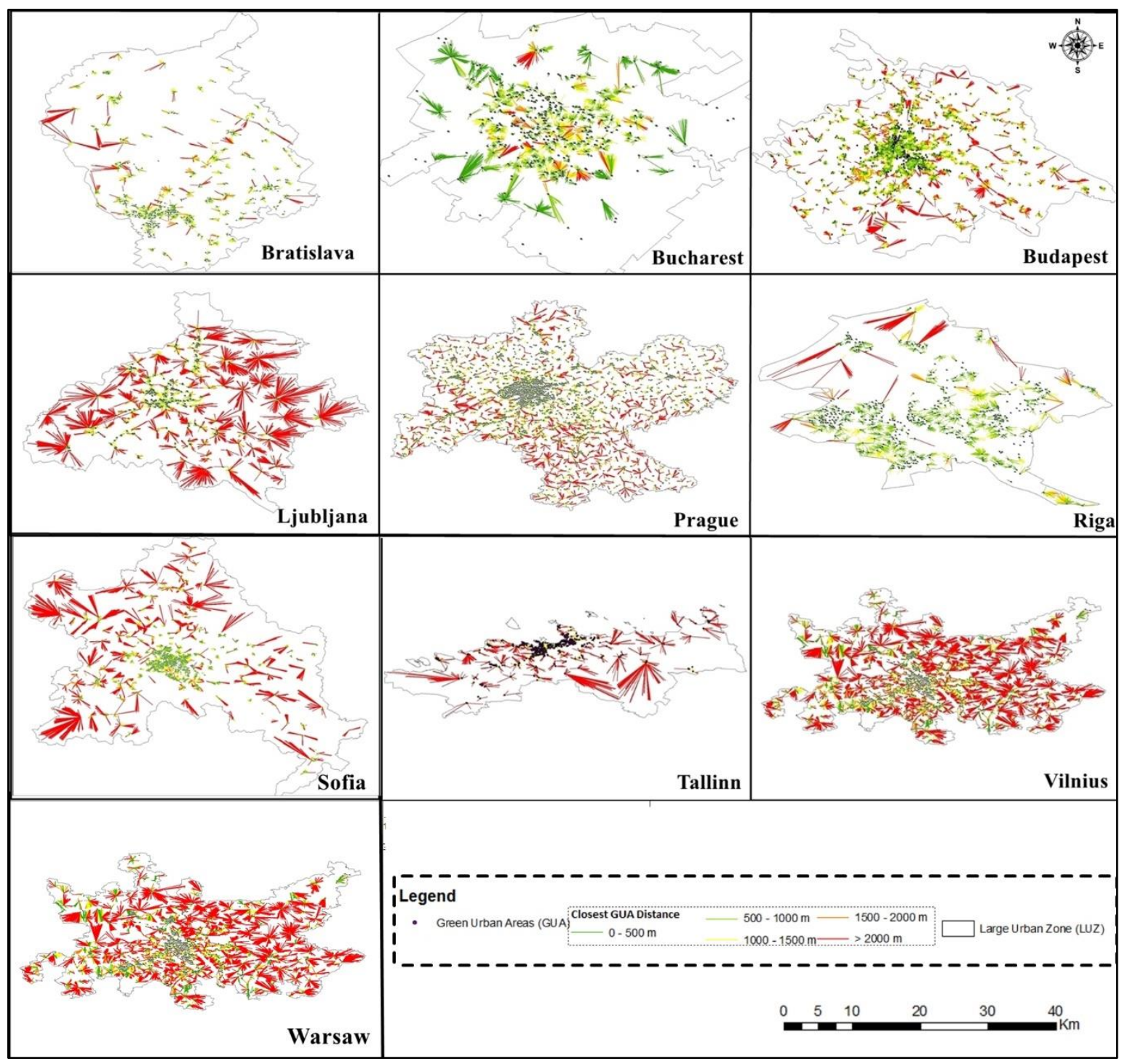

Figure 5 - Spatial accessibility patterns to GUA : Network Analysis - Closest Facility (Data source :GMES Urban Atlas, OSM)

As to the maximum and median distance from residential areas to green urban areas, the shortest median path is about $500 \mathrm{~m}$ being recorded by Riga, while the longest median path is observed for Warsaw and Ljubljana (see Fig. 6). Regarding the maximum distance a person has to travel to reach an urban area, the biggest value is obtained by Tallinn, at the opposite end being Bucharest. (see Fig. 6)

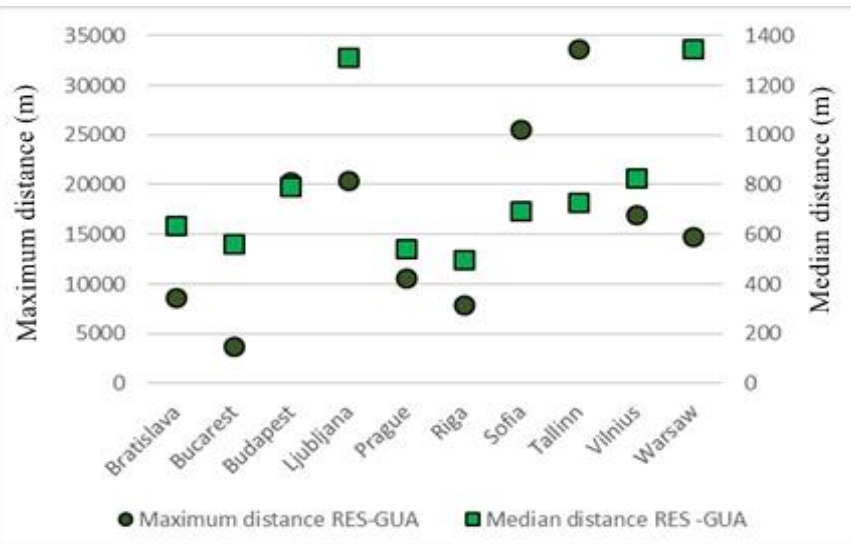

Figure 6 - Maximum and median distance to GUAs (Data Source : GMES Urban Atlas) 


\subsection{Discussions}

The fall of the communism and the transition to the liberal economy induced a lot of changes not only in the socio-economic system, but also in what concerns the way the urban planning was made in Eastern and Central European countries. Nevertheless, it should be take into account that the transition and transformation of these countries were not easy ones, as they were required to catch up with strong developed western European countries which have bigger financial power and do not necessarily need to prioritize where they invest their funds. Hence, more than 20 years after the change of regime, these countries still face problems in what concerns meeting the requirements of a sustainable development, as the results presented before showed us, at least in what concerns the accessibility of the population to green spaces. It is easy to observe, analysing the maps form figure 5, that there is a strong tendency that the accessibility to the green urban areas decrease form the inner centre to the peripheries, as the general trend is the clustering of GUAs around the initial core of the city, fact shown also in previous research which focused on modelling the patterns of land-use in European cities [4],[6].This is the result of the socialist heritage, as it was already mentioned, the urban planning focused on developing new industrial areas and new residential areas that would accommodate as much population as possible. No one denies the fact that the residential complexes during that period that were built did not forget to assure a small green area nearby, but with the fall of the socialist regime and the ascending of private market actors, the green urban areas felt into a semi-shadow as the main interest was to build as many residential and commercial areas as the law and the space itself allowed. Therefore, with laws that were still in process of keeping the pace with the transition process and with an increased demand of housing and commercial from the population, the green and open spaces were not the major point of interest. Consequently, the artificial areas increased and the green urban spaces stayed the same, in the most positive outcome, or even decreased in order to make place for residential, commercial or business centres, as a result of a loose control over the spatial development and a boom of the phenomenon of the urban sprawl, which resulted in high spatial disparities in what concerns the accessibility of population to the green urban areas. (see fig.5). In fact, one could note that the bigger the city and the intensity of the phenomenon of urban sprawl are, the bigger the distance towards the closest green area is (see fig. 5 - Ljubljana, Sofia, Vilnius etc.). Nevertheless, there are also some capital cities (see fig.5 - Bucharest, Budapest etc.) that show a better homogeneity in what concerns the spatial distribution of the green urban areas and therefore, there is a better equity regarding the accessibility of the population. Still, the peripheral zones show also some spatial discrepancies, fact that indicates that they also have problems in well-managing viable urban policies towards a sustainable development.

But taking into account also the graphics, one could note that despite Bucharest is having a good spatial distribution of the green urban areas, as showed before, the surface of green area per inhabitant is under the minimum demanded by the WHO (see fig.3), therefore even though there are no big problems in what concern the access of population to GUAs, their surface is very modest, fact which limits their benefits. Moreover, taking into consideration also the fact the growth rate during the period of study was low (see fig.4), we could say that despite an increasing promotion of the sustainable development 
at the European level, the national, regional and local policies of Romania does not focus yet on it. An opposite situation can be observed for the capital of Lithuania - Vilnius, as well as for the capital of Poland - Warsaw, which despite having the highest values for the green area/capita, they have important spatial disparities in assuring an equitable accessibility to all the population of the large urban zone, especially to the residential zones that are in the peripheral areas. In truth, few are the countries that switched to a liberal regime in 1989 and that focused on the preserving of semi-natural resources inside the high artificialized urban areas, as their attention was directed into developing the retail and business sector and leave behind the forced industrialisation that proved unreliable for a constant socio-economic progress. Therefore, if taken into account the growth rate of the surface and the number of the GUAs in the capital cities that were analysed, one could imply that the green urban areas were not a point of focus in the urban planning policies, the only urban area that records a higher value being Tallinn, at the other end with a decrease in GUAs being Vilnius.

Overall, analysing both the maps and the graphics, one could observe some common characteristic for all the analysed urban areas - the high degree of clustering of GUAs around the barycentre of the city and a decreasing accessibility towards them as the residential areas are farther from the urban core. Apart from that, one could not easily derive regional characteristics, take for example the Baltic countries - the capital of Estonia - Riga seems to have acquired a fairly good management in what concerns the spatial extent of the green urban areas, while the other two capital cities - Vilnius and Tallinn still face difficulties in providing a homogenous accessibility. Hence, the patterns of GUAs development seem rather random in all the capital cities that were analysed, except for their general tendency to concentrate around the barycentre. This is a result not only of a flow legislation, but also of the fact that the priority is being given to tertiary economic sector, which for the post-socialist city, represents the main driver of socioeconomic progress and a "chance" to align to the western cities. However, in the actual European and international dynamics were the sustainable development is the main point on the agenda, the Central and Eastern European countries should focus more on investing in it, the green urban areas being an important element for a greener city, due to their many socio-economic and cultural functionalities.

\section{CONCLUSION}

The results state the necessity of coherent development policies in what concerns the green urban spaces in the post-socialist capital cities of Central and Eastern Europe, as there are major differences regarding their availability to the population, as well as their quantitative aspects. There is a lack of spatial homogeneity in what concerns their spatial distribution patterns for all the ten urban areas analyzed. One could note a general particularity for all the analyzed urban areas in what concerns the spatial localization of GUAs: a general trend of clustering around the barycenter of the city, decreasing towards the periphery, but apart from that, the random pattern is quite often. Also, another sharedparticularity is the low growth rate of the green urban areas for the six years the analysis was conducted. Therefore, one could conclude that despite no regional particularities could easily be observed, all the cities analyzed still lack a well-conducted management of the GUAs, either in what concerns their quantitative aspects, either in what concerns their spatial distribution or in both of them. 
Summing up and taking into account the trend of urban sustainable development promoted by the European Union more attention should be done to the preserving of green urban areas as they represent the "nature" in the cities and therefore more investments should be directed into creating new green areas in order to assure equitable benefits for all the urban population (quantitative aspects, as well as spatial distribution patterns).

Finally, in what concern futures perspectives of the research and taking into account the results obtained, it could prove interesting adding to the study more urban areas, as well as more indexes in order to create a complex typology that could capture the not only the national and regional particularities in terms of both quantitative aspects and spatial distribution patterns, but could also highlight a different trajectory of the medium and smaller cities compared to the capital cities.

\section{REFERENCES}

[1]. Beatley, T., Green Urbanism: Learning from European Cities Island Press, Washington, DC, 2000

[2]. Comber, A., Brunsdon, C., Green, E., Using a GIS-based network analysis to determine urban greenspace accessibility for different ethnic and religious groups. Landscape and Urban Planning 86, 103-114, 2008

[3]. Dai, D., Racial/ethnic and socioeconomic disparities in urban green space accessibility: Where to intervene? Landscape and Urban Planning, 102(4), 234244, 2011

[4]. Fuller, R.A., Gaston, K.J., The scaling of green space coverage in European cities. Biology Letters 5, 352-355. doi:10.1098/rsbl.2009.0010, 2009

[5]. Nicholls, S., Measuring the accessibility and equity of public parks: a case study using GIS, Managing Leisure 6: 201-219, 2001.

[6]. Sandu A., Patterns of urban land-use in Eastern Europe-exploring GMES database using the location quotient, Lucrările Seminarului Geografic „Dimitrie Cantemir”, Nr. 33, Iaşi: Ed. Universităţii A1.I.Cuza, 2012.

[7]. Europe 2020 Strategy - https://ec.europa.eu/info/strategy/europeansemester/framework/europe-2020-strategy_en

[8]. World Health Organization, 'Urban Planning, Environment and Health: From Evidence to Policy Action', 2010

[9]. GMES Urban Atlas 2006 - mapping guide v2, EEA, 2006

[10]. GMES Urban Atlas datasets - http://land.copernicus.eu/local/urban-atlas

[11]. Open Street Map datasets - https://www.openstreetmap.org 